\title{
ANÁLISE MORFOMÉTRICA DE BACIA HIDROGRÁFICA UTILIZANDO DADOS DE DIFERENTES MODELOS DIGITAIS DE SUPERFICIE
}

\section{MORPHOMETRIC ANALYSIS OF WATERSHED USING DIFFERENT DIGITAL SURFACE MODELS}

Noemi De Oliveira Dias ${ }^{1}$, Vagner Souza Machado ${ }^{1}$, José Marcato Junior ${ }^{2}$, Lucas Prado Osco ${ }^{1}$, Ana Paula Marques Ramos ${ }^{1}$

${ }^{1}$ Universidade do Oeste Paulista - UNOESTE. ${ }^{2}$ Universidade Federal de Mato Grosso do Sul-UFMS.

E-mail: noemi_dias@outlook.com

RESUMO - A análise morfométrica de bacia hidrográfica é importante para subsidiar o desenvolvimento de estudos ambientais. Com o avanço das geotecnologias, os Modelos Digitais de Superfície (MDS), extraídos de imagens de satélite e processados em ambiente de Sistema de Informação Geográfica, têm consistido em uma importante fonte de dados para a análise morfométrica de bacias. Este estudo caracteriza a morfometria de bacia hidrográfica usando diferentes MDS. Adotou-se a bacia do rio Pirapozinho como objeto de estudo. Os achados desse trabalho revelam uma baixa propensão à enchente da bacia em análise. Também, notamos que podem existir variações nos parâmetros morfométricos de acordo com o MDS usado, ainda que sejam modelos de mesma resolução espacial.

Palavras-chave: Morfometria; Geotecnologias; Diagnóstico ambiental.

ABSTRACT - The morphometric analysis of the watershed is important to support the development of environmental studies. With the advancement of geotechnologies, Digital Surface Models (MDS), extracted from satellite images and processed in a Geographic Information System environment, have been an important source of data for the morphometric analysis of basins. This study characterizes watershed morphometry using different MDS. The Pirapozinho river basin was adopted as the object of study. The findings of this work reveal a low propensity to flood the basin under analysis. Also, we note that there may be variations in the morphometric parameters according to the MDS used, even though they are models of the same spatial resolution.

Keywords: Morfometry; Geotecnology; Environmental diagnosis. 


\section{INTRODUÇÃO}

Uma bacia hidrográfica é a área geográfica limitada por um divisor de águas, que a separa das bacias adjacentes e que serve de captação natural de água de precipitação por meio de superfícies vertentes (BORSATO; MARTONI, 2004). As características físicas de bacias hidrográficas se alteram ao decorrer do tempo sob a influência de dois fatores: de ordem natural e de ordem antrópica. O fator de ordem natural remete à pré-disposição do meio a degradação. O de ordem antrópica está relacionado com atividades humanas que interfere direta ou indiretamente nas condições ambientais da bacia (Lima et al.,2016).

A degradação ambiental que tem acontecido em bacias hidrográficas pode ser constatada em diversos estudos (CANDIDO et al., 2010; MENDONÇA et al., 2011; VIEIRA 2016 e BERLANDA, 2017). Na bacia hidrográfica do rio Pirapozinho, objeto desse estudo, a degradação ambiental é uma realidade, como mostra os estudos de Costa et al. (2014) e Rodrigues (2017).

Oliveira et al. (2010) salienta que, a análise morfométrica é fundamental para a realização de estudos ambientais em bacia hidrográfica. $\mathrm{Na}$ análise morfométrica descrevem-se os parâmetros morfológicos e seus processos, no intuito de diagnosticar mudanças, com ou sem interferência das atividades humanas (PISSARRA et al., 2010).

A morfometria tem como objetivo desenvolver a compreensão das grandezas, nas relações entre a causa e o efeito que se estabelecem entre as formas e nos processos pedológico e hidrológico, na formação da bacia hidrográfica (CHRISTOFOLLETI, 1974). As informações obtidas em um estudo morfométrico, como destacam Rodrigues e Adami (2005), Lima (2008), e Santos e Sobreira (2008), podem ser úteis para fins de planejamento ambiental e gestão de recursos hídricos, uma vez que os parâmetros calculados podem nortear o manejo de bacias com fins conservacionistas.
Os Sistemas de Informação Geográfica

(SIG) constituem-se em importantes geotecnologias que auxiliam na realização de estudos morfométricos, como mostram os estudos de Alves e Castro (2003), Santos e Sobreira (2008), Miguel et al. (2014), Silva et al. (2017) e Lopes et al. (2018). Atualmente, as ferramentas de geoprocessamento implementadas nos SIG otimizam o processo de análise de terreno em bacia hidrográfica. Com essas geotecnologias, tem-se um ambiente flexível, para a manipulação e análise da informação espacial (PARETA \& PARETA, 2011).

Nos últimos anos, cresceu o uso de dados de Sensoriamento Remoto para estudos de bacias hidrográficas (PARMA, 2007). Dentre esses dados, podemos citar os Modelos Digitais de Superfície (MDS), pois subsidiam diferentes estudos ambientais, como mostram Gasparini et al. (2013), Rocha Júnior et al. (2018) e Toniolo (2018).

Existem diversos MDS disponibilizados gratuitamente para estudos científicos e demais fins, dentre os quais podemos citar: Alos Palsar; Bare Earth; Aster GEM 2; e SRTM v3, que são resultados de projetos de agências internacionais, e os disponibilizados pela Secretaria do Meio Ambiente do Estado de São Paulo (SMA) e pelo Instituto de Pesquisas Espaciais, o TOPODATA. Todavia, não se tem conhecimento sobre a extração da morfometria de bacia hidrográfica na região do oeste do estado de São Paulo utilizando diferentes MDS e se há variações nos parâmetros morfométricos ao se considerar diferentes modelos. Diante do exposto, este estudo tem como objetivo a análise morfométrica da bacia hidrográfica do Rio Pirapozinho utilizando os MDS SRTM v3 e o modelo disponibilizado pela SMA.

\section{MATERIAIS E MÉTODOS}

\section{1 Áreas de Estudo}

A bacia hidrográfica do rio Pirapozinho está localizada no extremo oeste do Estado de São Paulo e abrange os municípios de Álvares Machado, Estrela do Norte, Mirante do Paranapanema, 
Pirapozinho, Presidente Bernardes, Sandovalina, Santo Anastácio e Tarabai. O Rio Pirapozinho, que dá nome a bacia hidrográfica, tem sua nascente no município de mesmo nome, e deságua no Rio Paranapanema, localizado ao sul do município de Sandovalina, na divisa territorial com o município de Mirante do Paranapanema.

\subsection{Aquisição e Processamento dos Dados}

Foram utilizados para delimitação automática e extração da rede de drenagem os modelos digitais de duas fontes distintas, ambos são disponibilizados gratuitamente para download. Um dos modelos é o da SMA com resolução espacial de 30 metros. Esse modelo "[...] foi gerado a partir das curvas de nível extraídas das cartas do IBGE, Instituto Geográfico e Geológico (IGG) e Departamento de Serviços Geográficos do Exército, na escala 1: 50.000 (projeto GISAT)".

O outro MDS considerado foi o SRTM v3, que é a terceira versão dos dados do projeto SRTM (Shuttle Radar Topography Mission), disponibilizado pelo Serviço Geológico dos Estados Unidos da América (USGS). O SRTM foi um projeto internacional liderado pela NGA (National GeospatialIntelligence Agency) e pela NASA (National Aeronautics and Space Administration) dos Estados Unidos. Esse projeto gerou um MDS para grande parte da superfície terrestre (USGS SRTM, 2019).

O MDS SRTM v3 possui resolução espacial de 30 metros e foi obtido através do uso de interferometria de passagem única. Duas antenas de radar diferentes adquiriram dois sinais ao mesmo tempo e o cálculo das elevações da superfície foi realizado por meio das diferenças entre os dois sinais (NASA SRTM, 2019). Os processamentos iniciais, do MDS SRTM v3, incluíram: aquisição de imagens no site da USGS, construção do mosaico com as imagens obtidas e recorte do MDS para a região de interesse. Posteriormente, o MDS SRTM v3 foi reprojetado no Sistema de coordenadas
SIRGAS 2000/UTM fuso 22 Sul. Todos os processamentos foram realizados no QGIS versão 2.18, desenvolvido pela Open Source Geospatial Foundation (OSGeo) e disponibilizado gratuitamente para download no site do desenvolvedor.

\subsection{Delimitação da Bacia Hidrográfica e extração da Rede de Drenagem}

A delimitação da Bacia Hidrográfica bem como a geração da rede de drenagem foram obtidas através do QGIS utilizando a extensão TauDEM versão 5.1.2 - Terrain Analysis Using Digital Elevation Model (http://hydrology.usu.edu/taudem/versions. html). Este consiste em um conjunto de ferramentas que permitem a delimitação de bacias hidrográficas de maneira automática, rápida e objetiva (Nicolete et al.,2015).

Os passos para obtenção dos limites da bacia hidrográfica consistem em: (1) remoção de depressões ou poços existentes no MDE, que são os pixels com valores muito baixos ou iguais a zero que podem comprometer a continuidade do fluxo da água - Algoritmo Pit Remove; (2) determinação do fluxo preferencial de escoamento da água, sendo atribuída a cada pixel presente na imagem uma única direção, dentre as oito possíveis, em relação aos pixels vizinhos para o fluxo hídrico - Algoritmo D8 Flow Directions; (3) obtenção do fluxo acumulado na superfície ferramenta D8 Contributing Area, que consiste na obtenção da área de contribuição a montante do ponto de exutório, esse definido por meio de um shapefille de ponto manualmente - Algoritmo D8 Contributing Area; (4) obtenção do limite da bacia em formato raster - ferramenta Stream Reach and Watershed, neste passo, simultaneamente, é também gerado a rede de drenagem da bacia em formato vetorial (shapefile de linha). Para a realização da análise morfométrica, os dados foram convertidos para a geometria de polígono.

\subsection{Parâmetros Morfométricos}

Os parâmetros morfométricos calculados foram: (1) área total; (2) 
perímetro; (3) coeficiente de compacidade; (4) comprimento do Rio principal; (5) comprimento total dos rios; (6) densidade de drenagem; (7) fator forma; (8) Ordem da bacia; (9) índice de circularidade; (10) coeficiente de manutenção; (11) declividade e (12) altitude da bacia (Quadro 1). Os MDS foram utilizados como dado de entrada à geração dos mapas de declividade e hipsometria (faixas de altitudes representadas por cores). A declividade foi calculada durante a delimitação da bacia na etapa (2), pois, além do fluxo hídrico, o algoritmo D8 Flow Directions gera a declividade usando o MDS. A representação da Declividade e da Altitude foi por meio de mapas temáticos, Mapa de Declividade e Mapa Hipsométrico, utilizando cinco intervalos distintos de cores que remetem a percepção visual de ordem.

Quadro 1. Parâmetros Morfométricos calculados para a Bacia Hidrográfica do Rio Pirapozinho.

\begin{tabular}{|c|c|c|}
\hline Parâmetro Morfométrico & $\begin{array}{c}\text { Conceito } \\
\end{array}$ & Equação \\
\hline A - Área total $\left(\mathrm{Km}^{2}\right)$ & $\begin{array}{l}\text { Representa a área de captação } \\
\text { disponível e, portanto, quanto maior } \\
\text { a área, maior poderá ser o volume } \\
\text { de precipitação entrando no sistema } \\
\text { bacia hidrográfica (FRANCO \& DAL } \\
\text { SANTO,2015). }\end{array}$ & --- \\
\hline$P$ - Perímetro (Km) & $\begin{array}{l}\text { Corresponde à medida do } \\
\text { comprimento da linha do divisor de } \\
\text { águas da Bacia e que delimita a área } \\
\text { da mesma (SMITH, 1950). }\end{array}$ & --- \\
\hline Ordem da Bacia & $\begin{array}{l}\text { O parâmetro ordem dos canais se } \\
\text { refere a uma classificação sobre o } \\
\text { grau de ramificações e/ou } \\
\text { bifurcações presentes em uma bacia } \\
\text { hidrográfica (CAMPOS et al., 2015). }\end{array}$ & --- \\
\hline $\begin{array}{l}\text { Kc - Coeficiente de } \\
\text { Compacidade }\end{array}$ & $\begin{array}{l}\text { O coeficiente de compacidade }(\mathrm{Kc}) \text {, } \\
\text { relaciona a forma da bacia com um } \\
\text { círculo e constitui a relação entre o } \\
\text { perímetro da bacia e a circunferência } \\
\text { de um círculo de área igual à da } \\
\text { bacia (Cardoso et al., 2006). }\end{array}$ & $K c=0,28 \times P / V A$ \\
\hline $\begin{array}{c}L_{x} \text {-Comprimento do Rio } \\
\text { principal }(\mathrm{Km})\end{array}$ & $\begin{array}{l}\text { Comprimento total do Rio principal } \\
\text { que compõe a bacia hidrográfica, } \\
\text { considerando toda sua sinuosidade, } \\
\text { desde sua nascente até a sua foz. }\end{array}$ & --- \\
\hline $\begin{array}{c}L_{T}-\text { Comprimento total dos } \\
\operatorname{rios}(\mathrm{Km})\end{array}$ & $\begin{array}{l}\text { Comprimento total em } \mathrm{Km} \text { obtido da } \\
\text { soma do comprimento do rio } \\
\text { principal e de todos os rios que } \\
\text { compõe a bacia (L). }\end{array}$ & $L_{T}=L_{X}+L$ \\
\hline $\begin{array}{l}\text { Dd-Densidade de Drenagem } \\
\qquad\left(\mathrm{Km} / \mathrm{Km}^{2}\right)\end{array}$ & $\begin{array}{l}\text { A densidade de drenagem é a } \\
\text { relação do comprimento total dos } \\
\text { rios com a área da bacia (SILVA et al., } \\
\text { 2004). Destina-se a comparação da } \\
\text { frequência de cursos de água } \\
\text { existentes em uma área, de tamanho } \\
\text { padrão (HORTON, 1945). }\end{array}$ & $D d=L_{T} / A$ \\
\hline F-Fator de forma & $\begin{array}{l}\text { O fator de forma (F) relaciona a } \\
\text { forma da bacia com a de um } \\
\text { retângulo, correspondendo à razão }\end{array}$ & $F=A / L^{2}$ \\
\hline
\end{tabular}




\begin{tabular}{|c|c|c|}
\hline & 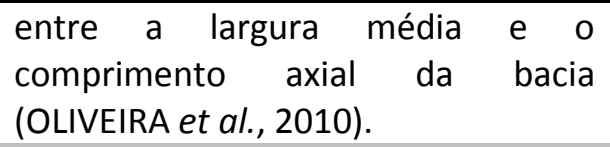 & \\
\hline Ic-Índice de circularidade & $\begin{array}{l}\text { O índice de circularidade, também } \\
\text { denominado por alguns autores } \\
\text { como índice de forma, representa a } \\
\text { relação existente entre o perímetro e } \\
\text { a área da bacia (CAMPOS et al., } \\
\text { 2015). O índice de circularidade (Ic) } \\
\text { tende para a unidade } 1,0 \text { à medida } \\
\text { que a bacia se aproxima da forma } \\
\text { circular e diminui sempre que a } \\
\text { forma se torna alongada (CARDOSO } \\
\text { et al., 2006). }\end{array}$ & $I c=12,57 * A / P^{2}$ \\
\hline $\begin{array}{l}\text { Cm-Coeficiente de } \\
\text { Manutenção }\left(m^{2}\right)\end{array}$ & $\begin{array}{l}\text { Representa a área mínima necessária } \\
\text { para manutenção de um metro de } \\
\text { escoamento (SCHUMM, } 1956 \text { apud } \\
\text { CHRISTOFOLETTI, 1974). }\end{array}$ & $C m=1 / D d \times(1000)$ \\
\hline Declividade & $\begin{array}{l}\text { A declividade é a inclinação da } \\
\text { superfície do terreno em relação à } \\
\text { horizontal, ou seja, a relação entre a } \\
\text { diferença de altura (dh) entre dois } \\
\text { pontos e a distância horizontal (dH) } \\
\text { entre esses pontos. É dada pelo } \\
\text { ângulo de inclinação (zenital) da } \\
\text { superfície do terreno em relação à } \\
\text { horizontal. Os valores de declividade } \\
\text { podem variar de } 0^{\circ} \text { a } 90^{\circ} \text {, e podem } \\
\text { também ser expressos em } \\
\text { porcentagem (AMBDATA). }\end{array}$ & Declividade $_{\text {graus }}=\operatorname{ArcTan}(d h / D h)$ \\
\hline
\end{tabular}

\section{RESULTADOS E DISCUSSÕES}

Os resultados encontrados para os parâmetros calculados foram sumarizados na Tabela 1. Os valores obtidos para o perímetro apresentaram uma variação de 9,14\% quando comparados os valores entre os MDS. O comprimento do Rio principal foi um dos parâmetros que apresentou pouca variação nos valores de um MDS em relação ao outro, apresentando uma variação de aproximadamente $3 \mathrm{~km}$ (3,03\%). A extensão do Rio principal é grande e está relacionada ao tamanho da bacia em extensão territorial. Esse parâmetro mostra a distância em Km da nascente até a foz. Brubacher et al. (2011) afirma que, quanto menor a distância da nascente à foz, maior é a possibilidade de enchentes, pois menor é à distância para a descarga de água. Diante dessa afirmação e dos valores obtidos para esse parâmetro, o risco potencial de enchentes na bacia estudada é consideravelmente baixo. 
Tabela 1. Resultados dos Índices Morfométricos da Bacia do Rio Pirapozinho.

\begin{tabular}{|c|c|c|c|}
\hline PARÂMETRO & MDE-SP & MDE SRTM 3 & VARIAÇÃO (\%) \\
\hline Área $\left(\mathrm{Km}^{2}\right)$ & 998,10 & 1002,70 & 0,46 \\
\hline Perímetro (Km) & 254,68 & 278,63 & 9,40 \\
\hline $\begin{array}{l}\text { Comp. Rio Principal } \\
(\mathrm{Km})\end{array}$ & 93,16 & 90,42 & 3,03 \\
\hline $\begin{array}{l}\text { Comp. total dos rios } \\
(\mathrm{Km})\end{array}$ & 835,63 & 1799,28 & 115,32 \\
\hline $\begin{array}{l}\text { Ordem Hierárquica da } \\
\qquad \text { Bacia }\end{array}$ & --- & 6 & --- \\
\hline $\begin{array}{l}\text { Kc - Coeficiente de } \\
\text { Compacidade }\end{array}$ & 2,26 & 2,46 & 9,14 \\
\hline $\begin{array}{l}\text { Dd - Densidade de } \\
\text { Drenagem }\left(\mathrm{Km} / \mathrm{Km}^{2}\right)\end{array}$ & 0,84 & 1,80 & 114,31 \\
\hline F- Fator de Forma & 0,115 & 0,12 & 6,61 \\
\hline $\begin{array}{l}\text { Ic - Índice de } \\
\text { Circularidade }\end{array}$ & 0,19 & 0,16 & 19,16 \\
\hline $\begin{array}{l}\mathrm{Cm} \text { - Coeficiente de } \\
\text { Manutenção }\left(\mathrm{m}^{2}\right)\end{array}$ & 1194,46 & 557,35 & 114,31 \\
\hline Altitude Mínima (m) & 258,58 & 269 & 4,03 \\
\hline Altitude Máxima (m) & 481,81 & 503 & 4,40 \\
\hline
\end{tabular}

O comprimento total dos rios foi $835,63 \mathrm{~km}$ no MDS-SMA e $1799,28 \mathrm{~km}$ no MDS-SRTM v3, o que representa uma variação de $115 \%$, sugerindo assim um maior detalhamento do MDS SRTM V3. Segundo a classificação proposta por Wisler e Brater (1964), a partir dos resultados obtidos, podese afirmar que a bacia do rio Pirapozinho é uma bacia de grande porte. Segundo esses autores, bacias com até $26 \mathrm{Km}^{2}$ podem ser consideradas como bacias pequenas enquanto, bacias com área superior a 10 milhas quadradas $\left(26 \mathrm{~km}^{2}\right)$ podem ser consideradas como bacias grandes.

De acordo com Villela \& Mattos (1975), a determinação da área da bacia é essencial para determinação dos outros parâmetros morfométricos. Segundo Tucci (1997), a área de uma bacia hidrográfica é decisiva na sua resposta hidrológica, sendo que, ao desprezarmos outros fatores e analisarmos apenas área, podemos concluir que quanto maior a área de uma bacia hidrográfica maior será o tempo para que a água de escoamento superficial atinja o ponto de exutório e, consequentemente, menor será a probabilidade de ocorrência de picos de enchentes.

Analisando os dados obtidos nos dois MDS a variação da área da bacia foi de apenas $0,46 \%$, resultando em uma pouca diferença. Os resultados para esse parâmetro, na delimitação tanto com MDSSMA quanto MDS SRTM V3, quando analisado isoladamente, demonstram que a Bacia do Rio Pirapozinho possui uma grande área de drenagem e, consequentemente, pouco propensa a inundações e picos de enchentes.

A ordem hierárquica da bacia do Rio Pirapozinho, a partir dos dados obtidos com o MDS SRTM v3 demonstra que a bacia é 6a ordem segundo a classificação proposta por Strahler em 1952 (apud CHRISTOFOLETTI, 
1980), uma indicação de que a bacia é bastante ramificada. Olszevski et. al. (2004) considera que, quanto mais ramificada a rede mais eficiente será a drenagem. Em uma bacia com elevada ramificação, segundo Villela \& Matos (1975), a água precipitada, após iniciar o escoamento superficial, vai percorrer uma extensão menor para encontrar um curso d'água. A partir desse parâmetro, a bacia possui tendência à enchente, pois quanto menor a ordem dos rios, menor também a tendência de enchentes nas bacias hidrográficas (BOESE \& TOMALACK, 2013).

O Coeficiente de Compacidade $(\mathrm{Kc})$ foi de 2,26 para o MDS-SMA e de 2,46 para o MDS SRTM v3, apresentando um valor médio de 2,3604 e uma variação de $9,14 \%$ de um MDS em relação a outro. O coeficiente de compacidade $(\mathrm{Kc})$ relaciona a forma da bacia com um círculo e constitui a relação entre o perímetro da bacia e a circunferência de um círculo de área igual à da bacia (Cardoso et al., 2006). Segundo Oliveira et al. (2010) bacias hidrográficas cuja forma se aproxima à de um círculo, tendem a proporcionar a conversão do escoamento superficial para um trecho pequeno do rio principal; assim, quanto mais próximo a 1 for este índice maior a potencialidade de picos de enchentes na bacia hidrográfica. Os valores obtidos para esse parâmetro assegura que a bacia é bastante irregular e possui pouquíssima similaridade com um círculo, os valores superiores a 2,26 indicam que a bacia é pouco propensa a enchentes em condições normais de precipitação. Uma bacia terá maior propensão a enchentes mais acentuadas quando seu Kc for mais próximo da unidade (SANTOS et al., 2018).

Outro parâmetro que indica a forma da bacia é o índice de circularidade (IC), a relação existente entre o perímetro e a área da bacia pode variar de 0 a 1 sendo que, valores para esse parâmetro muito próximos de 1 indicam que a bacia é similar a um círculo. Schumm (1956), afirma que a bacia tende a ser mais circular favorecendo os processos de inundação (picos de cheias) quando os valores para esse parâmetro são superiores a 0,51 e valores inferiores a 0,51 sugerem que a bacia tende a ser mais alongada contribuindo para o processo de escoamento. Embora a variação desse índice fosse de quase $20 \%$ entre os dois MDS estudados, os valores para esse parâmetro se mantiveram abaixo de 0,51 indicando que a bacia não possui forma circular e pouco propensa aos processos de inundação.

O Fator de forma foi outro índice que demonstrou que a bacia do Rio Pirapozinho é pouco propensa a enchentes. Uma bacia com $F$ baixo possui menor propensão a enchentes que outra com a mesma área, mas com $F$ maior (OLIVEIRA et al. 2010). Isso em virtude de que, em uma bacia estreita e longa ( $F$ baixo), ocorre menor possibilidade de ocorrência de chuvas intensas cobrindo, simultaneamente, toda a sua extensão (OLIVEIRA et al. 2010). Os valores para esse parâmetro variaram de $6,6 \%$ de um MDS em relação ao outro (Tabela 1). De acordo com Villela e Mattos (1975), quanto mais próximo de 1 for o fator de forma mais circular é a bacia e maior é a sua tendência a gerar enchentes rápidas e acentuadas.

A Densidade de Drenagem na Bacia do Rio Pirapozinho, seguindo a classificação proposta por Beltrame (1994), é mediana, pois nos dados obtidos por ambos MDS a Dd se manteve entre 0,50 e $2,00 \mathrm{Km} / \mathrm{Km}^{2}$. Este parâmetro expressa a quantidade de canais disponíveis para o escoamento, de forma que quanto mais canais presentes na bacia, mais rápido a água precipitada atinge o exutório (FRANCO; DAL SANTOS 2015). Assim, os valores obtidos para esse parâmetro demonstram que, ainda que baixa, a bacia pode apresentar picos de enchentes e inundações em seu ponto de exutório. Ainda que, a densidade de drenagem de ambos os MDS se manteve em uma mesma classificação é importante destacar a variação expressiva que se obteve para esse parâmetro, enquanto que no MDS-SMA a Dd foi igual a $0,84 \mathrm{~km} / \mathrm{Km}^{2}$, no MDS SRTM v3 a Dd foi igual a $1,80 \mathrm{~km} / \mathrm{Km}^{2}$, uma variação de quase $115 \%$ (Tabela 1). Essa diferença está 
associada ao comprimento total dos rios que compõe a bacia, pois o outro parâmetro que é utilizado para a obtenção da Densidade de Drenagem, o perímetro, apresentou pouca variação.

Com relação às classes hipsométricas, foi escolhida uma divisão com equidistância de 50 em 50 metros para uma análise mais detalhada do relevo, resultando em cinco classes de altitude como é possível observar nas Figura 1 e 2. Com o MDS-SMA, a Bacia Hidrográfica do Rio Pirapozinho, apresentou como altitude mínima $258,58 \mathrm{~m}$ e como altitude máxima 481,81 m. Com o MDS SRTM v3 os dados obtidos para altitude mínima foi de $269 \mathrm{~m}$ e para altitude máxima foi de 503 m. A variação dos resultados de um MDS em relação a outro, para altitude mínima e máxima, foi $4,03 \%$ e $4,40 \%$, respectivamente.

De acordo com Woodcock (1976) e Castro Jr. (2001), altitudes elevadas podem acarretar diferenças de temperatura média, podendo chegar a uma variação de até $1,5^{\circ}$ C. Em altitudes mais elevadas a temperatura será mais baixa, e em altitudes mais baixas a temperatura será maior. Isso, segundo esses autores, pode provocar variações na evaporação e transpiração, isso porque em altitudes elevadas, apenas pequena quantidade de energia é utilizada para evaporar a água; em altitudes baixas, quase toda a energia absorvida é usada para evaporação da água. As altitudes elevadas tendem a receber maior quantidade de precipitação, além de a perda de água ser menor (CARDOSO et al., 2006).

A bacia do Rio Pirapozinho possui intervalos de declividade que vão de 0 a $18,1^{\circ}$ no Mapa de Declividade gerado a partir do MDS- SMA (Figura 3) e intervalos que vão de 0 a $24,6^{\circ}$ no Mapa de Declividade gerado a partir do MDS SRTM $v 3$.

Figura 1. Mapa Hipsométrico Bacia Rio Pirapozinho.

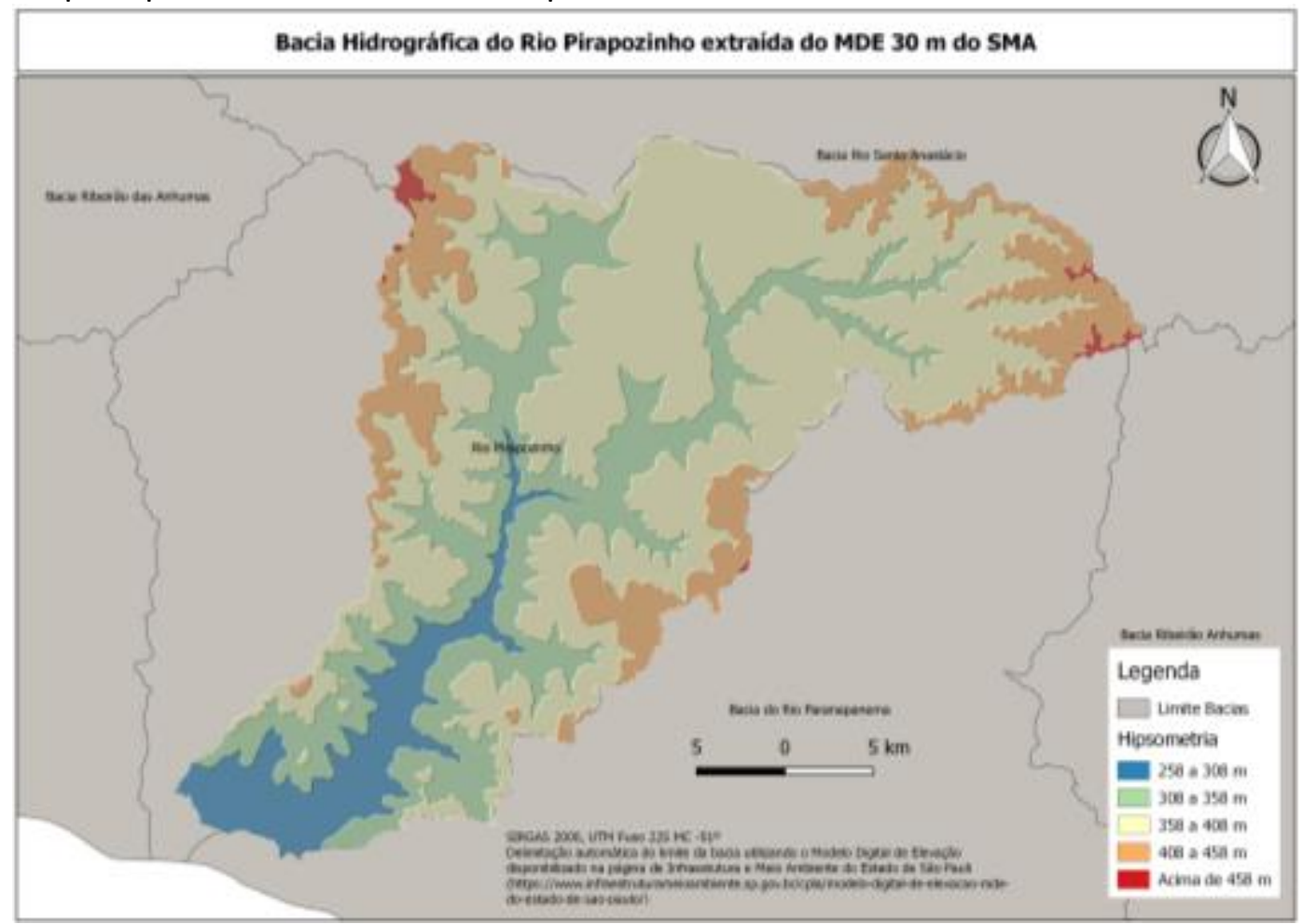

Fonte: Autores (2019) 
Figura 2. Mapa Hipsométrico Bacia Rio Pirapozinho (SRTM v3).

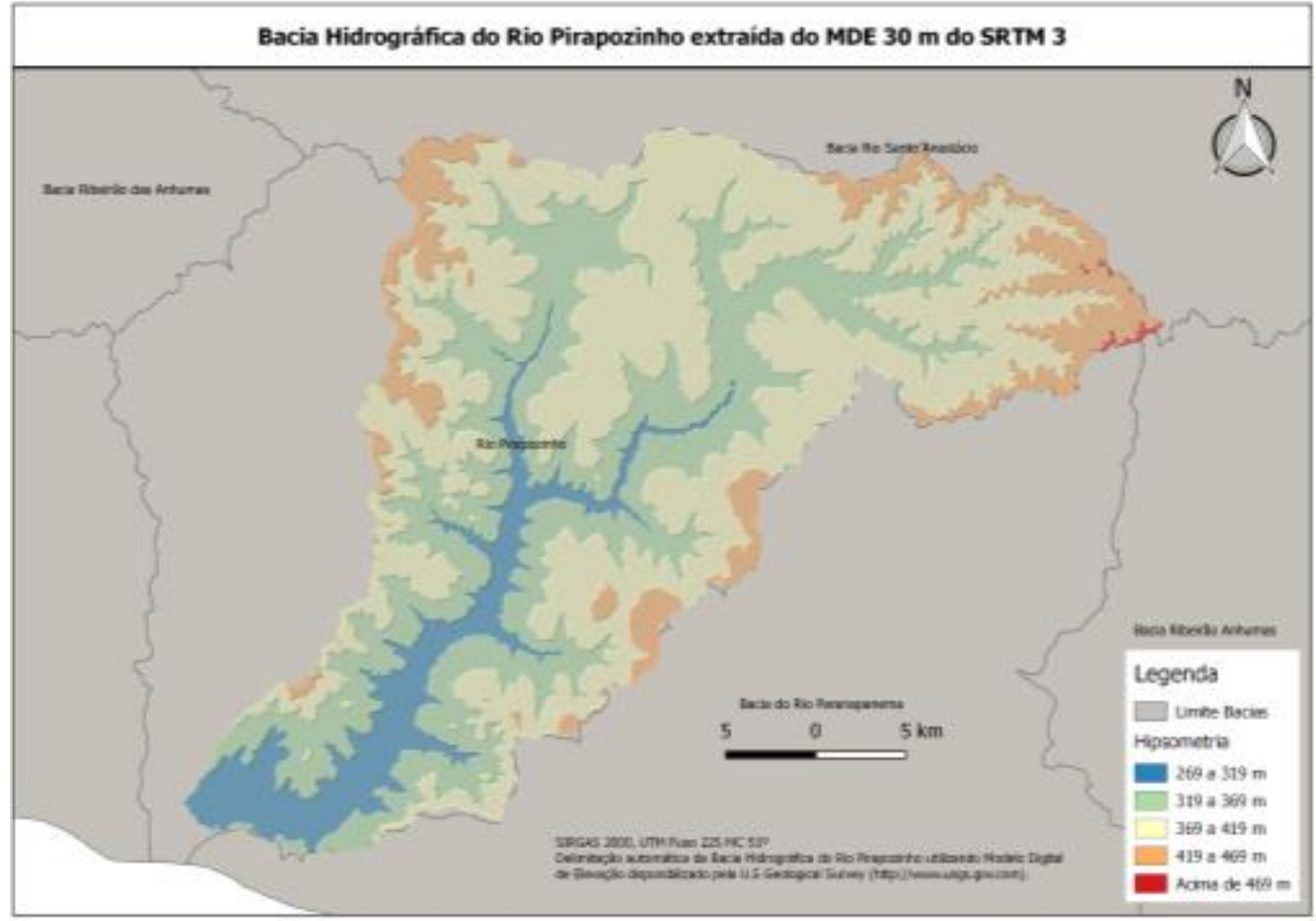

Fonte: Autores (2019)

Figura 3. Mapa de Declividade (MDS-SMA).

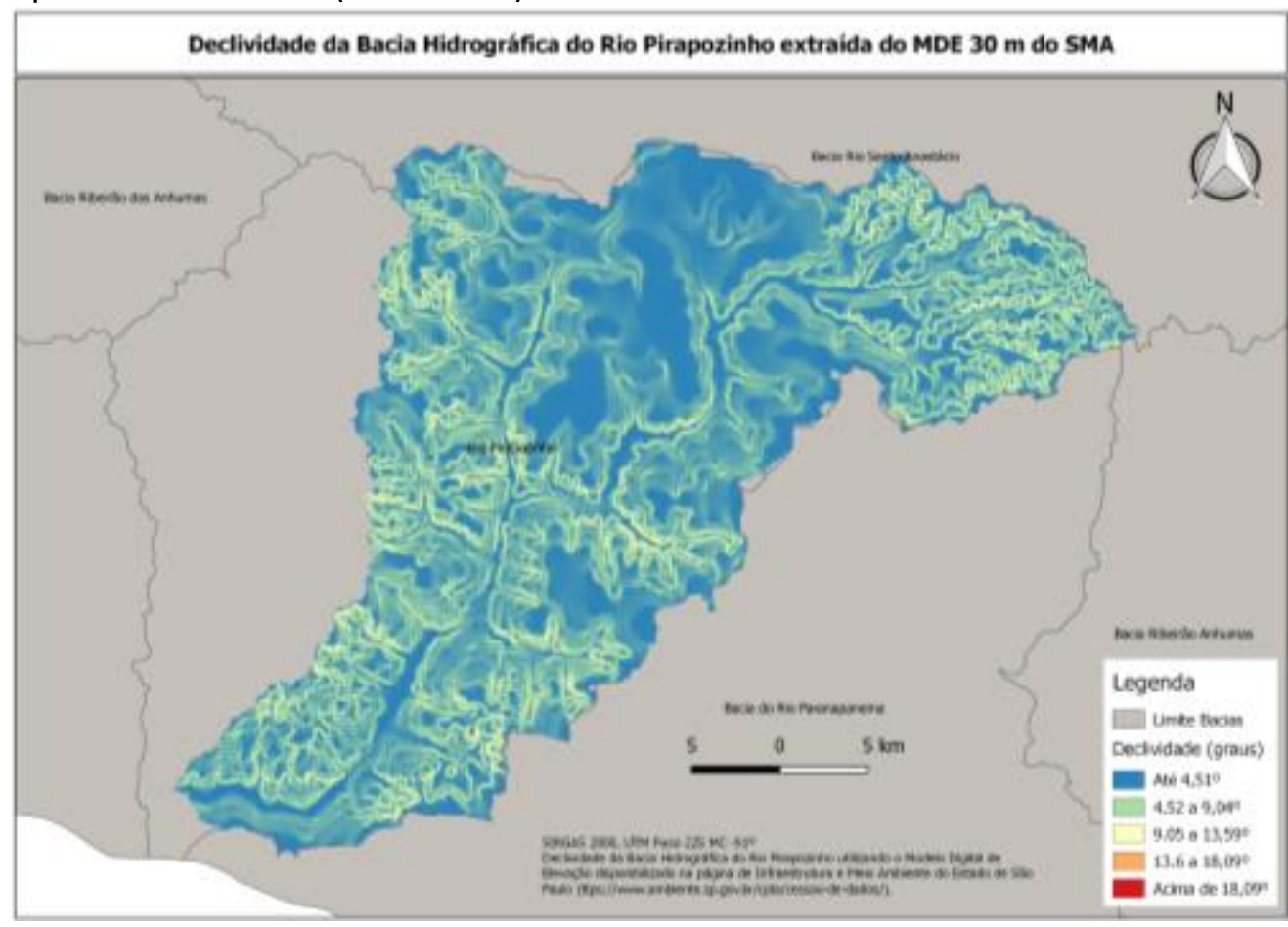

Fonte: Autores (2019) 
Figura 4. Mapa de Declividade (MDS SRTM v3).

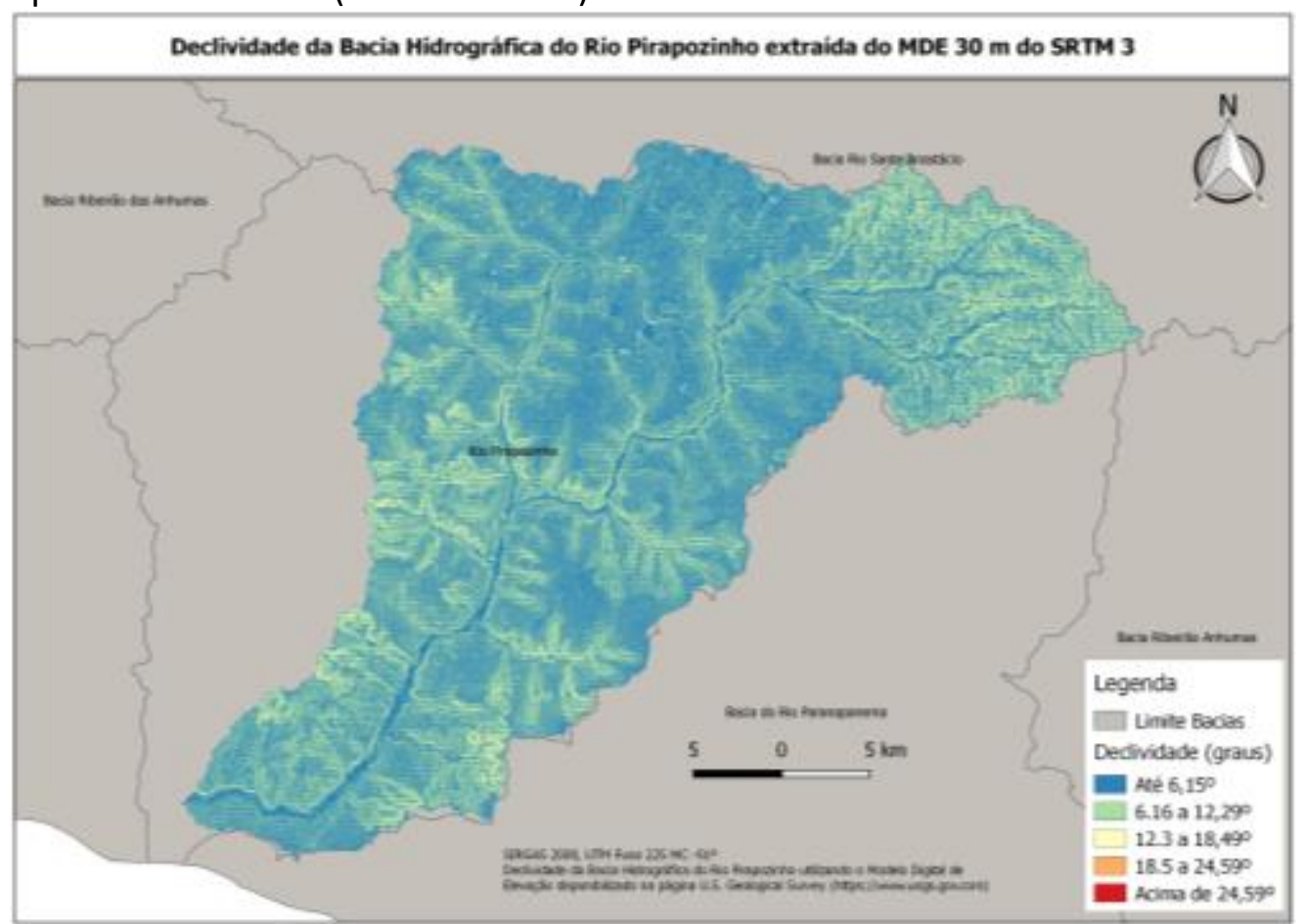

Fonte: Autores (2019)

A Empresa Brasileira de Pesquisa Agropecuária (Embrapa) classifica a Declividade em 6 classes (Tabela 2). Assim, ao analisarmos a Declividade a partir dos dados do MDS-SMA as formas de relevo que ocorrem na Bacia Hidrográfica do Rio Pirapozinho são Plano, Suave Ondulado e Ondulado. No entanto, quando analisamos os dados obtidos do MDS SRTM v3, as formas de Relevo são Plano, Suave Ondulado, Ondulado e Forte Ondulado.

Segundo Cardoso et al. (2006), a declividade influencia a relação entre a precipitação e o deflúvio da bacia hidrográfica, sobretudo devido ao aumento da velocidade de escoamento superficial, reduzindo a possibilidade da infiltração de água no solo. Assim, em um relevo mais acentuado, a água irá escoar superficialmente em uma velocidade mais alta do que em um relevo plano, por exemplo. Portanto, um menor volume de água se infiltra no solo, desse modo, um maior volume de água chega ao corpo hídrico e é direcionada ao ponto de exutório da bacia podendo provocar picos de enchentes. Podemos considera que, mais uma vez o MDS SRTM v3 possui maior detalhamento, revelando uma forma de relevo que não foi possível obter através do MDS-SMA.

Tabela 2. Classificação de declividade pela Embrapa.

\begin{tabular}{cc}
\hline Declividade (\%) & Discriminação \\
\hline $0-3$ & Plano \\
$3-8$ & Suave Ondulado \\
$8-20$ & Ondulado \\
$20-45$ & Forte Ondulado \\
$45-75$ & Montanhoso \\
$>75$ & Escarpado \\
\hline
\end{tabular}

Fonte: Embrapa (2009).

\section{CONSIDERAÇÕES FINAIS}

Com exceção aos parâmetros ordem hierárquica e densidade de drenagem, os demais parâmetros apresentaram faixas de valores que indicam que a Bacia Hidrográfica do Rio Pirapozinho é pouco propensa aos processos de inundações e picos de enchentes. A análise entre os MDS-SMA e MDS SRTM v3 indica que MDS ainda que possuam a mesma resolução espacial podem apresentar variações significativas em seus dados.

Todo o estudo foi realizado utilizando ferramentas e softwares de SIG livres, que se 
mostraram bastante úteis e práticos para o processamento de imagens e para o estudo morfométrico de bacias hidrográficas.

\section{AGRADECIMENTOS}

Ao CNPq pelo apoio financeiro para o desenvolvimento deste projeto na modalidade de bolsa de iniciação tecnológica.

\section{REFERÊNCIAS}

ALVES, J. M. de P.; CASTRO, P. de T. A. Influência de feições geológicas na morfologia da bacia do Rio do Tanque (MG) baseada no estudo de parâmetros morfométricos e análise de padrões de lineamentos. Revista Brasileira de Geociências, v.33, n.2, p.117124, 2003. https://doi.org/10.25249/03757536.2003332117124

ALVES, W.S.; SCOPEL, I.; MARTINS, A. P.; MORAIS, W.A. M. Análise morfométrica da bacia do Ribeirão das Abóboras - Rio Verde (GO). São Paulo, UNESP, Geociências, v. 35, n. 4, p.652-667, 2016.

AMBDATA. Variáveis Ambientais para Modelagem de Distribuição de Espécies. Disponível em: http://www.dpi.inpe.br/Ambdata/declividade gradiente.php. Acesso em: 8 ago. 2019.

BERLANDA, A.. Qualidade ambiental da bacia hidrográfica do Rio Desquite em Otacílio Costa/SC. 2017. Dissertação (Mestrado) Universidade do Estado de Santa Catarina UDESC, Lages, SC, 2017.

BORSATO, F. H.; MARTONI, A. M. Estudo da fisiografia das bacias hidrográficas urbanas no Município de Maringá, Estado do Paraná. Acta Scientiarum, Human and Social Sciences, Maringá,PR, ano 2004, v. 26, n. 2, p. 273-285, 2004.

https://doi.org/10.4025/actascihumansoc.v26 $\underline{\mathrm{i} 2.1391}$

CAMPOS, S. et al. Caracterização morfométrica da microbacia do rio Bauru/SP obtida por técnicas de geoprocessamento.
Revista Interespaço - Revista de Geografia e Interdisciplinalidade, Grajaú/MA, ano 2015, v.1, $\quad$ n.3, p.222-234. https://doi.org/10.18766/24466549/interespaco.v1n3p222-234

CARVALHO, J. R. M. et al. Proposta e validação de indicadores hidroambientais para bacias hidrográficas: estudo de caso na sub-bacia do alto curso do Rio Paraíba, PB.Sociedade \& Natureza, Uberlândia/MG, 2011. Disponível em:

http://www.scielo.br/scielo.php?script=sci_ar ttext\&pid=S1982-45132011000200012.

Acesso em: 6 ago. 2019.

CARDOSO, C.A.; DIAS, H.C.T.; SOARES, C.P.B.; MARTINS, S.V. Caracterização morfométrica da bacia hidrográfica do Rio Debossan, Nova Friburgo, RJ. Revista Árvore, v. 30, n. 2, p. 241- 2482006. https://doi.org/10.1590/S0100$\underline{67622006000200011}$

COSTA, A. P.; OSCO, L. P.; COLADELLO, R.; BOIN, M. R.. Avaliação do uso e ocupação na cabeceira do rio Pirapozinho (SP). Colloquium Humanarum, Presidente Prudente, v. 11, n. 2, p.58-65, maio/ago., 2014. https://doi.org/10.5747/ch.2014.v11.n2.h158

CASTRO JR., E. O papel da fauna endopedônica na estruturação física dos solos e o seu significado para a hidrologia de superfície. 2001. 150 f. Dissertação (Mestrado em Geografia) - Universidade Federal do Rio de Janeiro, Rio de Janeiro, 2001.

CHRISTOFOLETTI, A. A análise de bacias hidrográficas. In: CHRISTOFOLETTI, Antonio. Geomorfologia. São Paulo: Edgard Blücher, EDUSP, 1974.

EMBRAPA. Centro Nacional de Pesquisa de Solos (Rio de Janeiro, RJ). Sistema brasileiro de classificação de solos. Rio de Janeiro: EMBRAPA-SPI, 2009. 412p. ISBN 85- 8586404-4. 
FRANCO, A. C. V.; DAL SANTO, M. A. Contribuição da morfometria para o estudo das inundações na sub-bacia do rio Luís Alves/SC. Mercator (Fortaleza), v. 14, n. 3, p. 151-167, 2015. https://doi.org/10.4215/RM2015.1403.0009

GASPARINI, K. A. C. et al. Técnicas de Geoprocessamento e Sensoriamento Remoto Aplicadas na Identificação de Conflitos do Uso da Terra em Seropédica-RJ. Floresta e Ambiente, v. 20, n. 3, p. 296-306, 2013. https://doi.org/10.4322/floram.2013.030

ROCHA JÚNIOR, José Antônio Lima et al. Aplicação de modelos digitais de elevação (MDE) na caracterização das áreas mais susceptíveis à erosão na microbacia Capitão Poço. PDVAGRO, 2018.

https://doi.org/10.31692/2526-

7701.IIICOINTERPDVAGRO.2018.00028

HORTO, R. E. Erosional development of streams and their drainage basins: hydrophysical approach to quantitative morphology. Bull Geol Soc Amer 5, 275-370, $1945 . \quad$ https://doi.org/10.1130/00167606(1945)56[275:EDOSAT]2.0.CO;2

LI, Z.; ZHU, Q.; GOLD, C. M. Digital terrain modelling. principles and methodology. New York: $\quad$ CRC Press,. 2005. 340 p.https://doi.org/10.1201/9780203357132

LIMA, G. A. Bacia Hidrográfica como unidade de Planejamento e Gestão: Estudo de Caso Ribeirão Isidoro. IBEAS - Instituto Brasileiro de Estudos Ambientais, [S. I.], v.24, nov., 2016. Disponível em: https://www.ibeas.org.br/congresso/Trabalho s2016/VIII-074.pdf. Acesso em: 5 ago. 2019.

MEDONÇA, F.; MARQUES, G. S.. Degradação ambiental e qualidade da água em bacia hidrográfica de abastecimento público: Rio Timbú - PR. Entre-Lugar, Dourados-MS, ano 2, n. 3, p. 111-136, 2011.
NICOLETTI, D. A. P. et al. Delimitação automática de uma bacia hidrográfica utilizando MDE TOPODATA: aplicações para estudos ambientais na região da Cuesta de Botucatu - SP. In: SIMPÓSIO BRASILEIRO DE SENSORIAMENTO REMOTO - SBSR, 17., João Pessoa-PB. Anais [...]. João Pessoa: INPE, 2015

LOPES, I.; LEAL, B. G.; RAMOS, C.M. C. Morphometric characterization of the basin in the semi-arid region of Pernambuco using SRTM data in free software. Journal of Hyperspectral Remote Sensing, v. 8, () p. 3140, 2018.

OLSZEVSKI, N.; COSTA, L. M.; FERNANDES FILHO, E. I.; RUIZ, H. A.; ALVARENGA, R. C.; CRUZ, J. C. Morfologia de agregados do solo avaliada por meio de análise de imagens. Revista Brasileira de Ciência do Solo, Viçosa, MG, v. 28, n. 5, p. 901-909, 2004. https://doi.org/10.1590/S0100-

$\underline{06832004000500012}$

PARETA, K., PARETA, U., Quantitative Morphometric Analysis of a Yamuna Basin, India using ASTER (DEM) Data and GIS, International Journal of Geomatics and Geosciences, v. 2, p. 248- 269, 2011.

PISSARRA, T. C. T.; RODRIGUES, F. M.; POLITANO, W; GALBIATTI, J. A. Morfometria de microbacias do Córrego Rico, afluente do Rio Mogi-Guaçu, Estado de São Paulo, Brasil. Revista Árvore, Viçosa/MG, v. 34, n. 4, p. 669676, jul./ago. 2010. https://doi.org/10.1590/S0100-

67622010000400011

RODRIGUES, B. M. Cartografia aplicada à análise ambiental de bacia hidrográfica: um estudo de caso na bacia do rio Pirapozinho. 2017. 119 f. Dissertação (Mestrado em Meio Ambiente e Desenvolvimento Regional) Universidade do Oeste Paulista, Presidente Prudente, 2017. 
SANTOS. C. A.; SOBREIRA, F. G. Análise morfométrica como subsídio ao zoneamento territorial: o caso das bacias do Córrego Carioca, Córrego do Bação e Ribeirão Carioca na região do Alto Rio das Velhas-MG. Revista Escola de Minas, v.61, n.1, p.77-85, 2008. https://doi.org/10.1590/S037044672008000100013

SANTOS, A. M.; TARGA, M.S.; BATISTA, G. T.; DIAS, N. W.. Análise morfométrica das subbacias hidrográficas Perdizes e Fojo no município de Campos do Jordão, SP, Brasil. Revista Ambiente \& Água - An Interdisciplinary Journal of Applied Science, v. 7, n. 3, 2012. https://doi.org/10.4136/ambiagua. 945

SCHUMM, S. A. Evolution of drainage systems and slopes in badlands of Perth Amboy. Geological Society of America Bulletin, v. 67, n. 5, p. 597-646, $1956 . \quad$ https://doi.org/10.1130/00167606(1956)67[597:EODSAS]2.0.CO;2

SILVA, A. M.; SCHULZ, H. E.; BARBOSA, C. P. Erosão e Hidrossedimentologia em Bacias hidrográficas. São Carlos: RiMa., 2004. 141p.

SILVA, C. T. S.; RIBEIRO FILHO, J. C.; SILVA, P. C. M.; LEMOS FILHO, L. César de Aquino; BRASIL, José B. B.. Caracterização morfométrica, uso e ocupação de uma bacia hidrográfica. Revista Engenharia na Agricultura, Viçosa,MG, v.25, n.05, p.436-444, 2017.

https://doi.org/10.13083/reveng.v25i5.828

SILVA, G. C. et al. Caracterização morfométrica da bacia hidrográfica do Riacho Rangel-Piauí, Brasil. Enciclopédia Biosfera, Centro Científico Conhecer - Goiânia, v. 15 n. 28; p. 2018. https://doi.org/10.18677/EnciBio 2018B22

SMITH, K. G. Standards for grading texture of erosional topography. American Journal of Science, n. 248, p. 655-668, 1950. https://doi.org/10.2475/ajs.248.9.655
TONELLO, K. C.; DIAS, H. C. T.; SOUZA, A. L.; ALVARES, C. A.; RIBEIRO, S.; LEITE, F. P. Morfometria da Bacia Hidrográfica da Cachoeira das Pombas, Guanhães - MG. Revista Árvore, v. 30, n. 5, p. 849-857, 2006. https://doi.org/10.1590/S0100$\underline{67622006000500019}$

VIEIRA, C. D.; OLIVEIRA, A. E. F.; ALVES, W. G.; LEÃO, O. M.R. Análise da degradação ambiental na bacia hidrográfica do Rio Alcântara no município de São Gonçalo, leste metropolitana do Rio de Janeiro. Revista Equador (UFPI), v. 5, n. 4, p. 93-105, 2016.

WISLER, C. O.; BRATER, E. F. Hidrologia. Rio de Janeiro: Ao Livro Técnico, 1964. 484 p. 